\title{
Genome-level homology and phylogeny of Shewanella (Gammaproteobacteria: Iteromonadales: Shewanellaceae)
}

\author{
Rebecca B Dikow ${ }^{1,2}$
}

\begin{abstract}
Background: The explosion in availability of whole genome data provides the opportunity to build phylogenetic hypotheses based on these data as well as the ability to learn more about the genomes themselves. The biological history of genes and genomes can be investigated based on the taxomonic history provided by the phylogeny. A phylogenetic hypothesis based on complete genome data is presented for the genus Shewanella (Gammaproteobacteria: Alteromonadales: Shewanellaceae). Nineteen taxa from Shewanella (16 species and 3 additional strains of one species) as well as three outgroup species representing the genera Aeromonas (Gammaproteobacteria: Aeromonadales: Aeromonadaceae), Alteromonas (Gammaproteobacteria: Alteromonadales: Alteromonadaceae) and Colwellia (Gammaproteobacteria: Alteromonadales: Colwelliaceae) are included for a total of 22 taxa.

Results: Putatively homologous regions were found across unannotated genomes and tested with a phylogenetic analysis. Two genome-wide data-sets are considered, one including only those genomic regions for which all taxa are represented, which included 3,361,015 aligned nucleotide base-pairs (bp) and a second that additionally includes those regions present in only subsets of taxa, which totaled 12,456,624 aligned bp. Alignment columns in these large data-sets were then randomly sampled to create smaller data-sets. After the phylogenetic hypothesis was generated, genome annotations were projected onto the DNA sequence alignment to compare the historical hypothesis generated by the phylogeny with the functional hypothesis posited by annotation.

Conclusions: Individual phylogenetic analyses of the 243 locally co-linear genome regions all failed to recover the genome topology, but the smaller data-sets that were random samplings of the large concatenated alignments all produced the genome topology. It is shown that there is not a single orthologous copy of $16 \mathrm{~S}$ rRNA across the taxon sampling included in this study and that the relationships among the multiple copies are consistent with $16 \mathrm{~S}$ rRNA undergoing concerted evolution. Unannotated whole genome data can provide excellent raw material for generating hypotheses of historical homology, which can be tested with phylogenetic analysis and compared with hypotheses of gene function.
\end{abstract}

\section{Background}

Shewanella is a genus of marine and freshwater gramnegative Gammaproteobacteria within the monogeneric family Shewanellaceae Ivanova et al., 2004. While members of Shewanella have been recognized since 1931 (e. g. Achromobacter putrefaciens Derby and Hammer 1931 now Shewanella putrefaciens), the genus Shewanella has

\footnotetext{
Correspondence: rbudinoff@uchicago.edu

'Committee on Evolutionary Biology, The University of Chicago, Chicago, IL, USA

Full list of author information is available at the end of the article
}

only been recognized with its present name since 1985 [1] and 39 of the 52 currently recognized species have been described since 2000 [2]. There are also multiple strains that are commonly studied but have not been given a proper name (some of these have been included below and will be referred to by their strain number). Members of Shewanella have been described from diverse habitats, including deep cold-water marine environments to shallow Antarctic Ocean habitats to hydrothermal vents and freshwater lakes (see Table 1[1,3-21]). Shewanella has been of great interest due to the ability
C Biomed Central

(c) 2011 Dikow; licensee BioMed Central Ltd. This is an Open Access article distributed under the terms of the Creative Commons Attribution License (http://creativecommons.org/licenses/by/2.0), which permits unrestricted use, distribution, and reproduction in any medium, provided the original work is properly cited. 
Table 1 Taxon table and Mauve results

\begin{tabular}{|c|c|c|c|c|c|c|c|c|}
\hline \multirow[b]{2}{*}{ Taxon } & \multirow[b]{2}{*}{$\begin{array}{l}\text { RefSeq } \\
\text { accession }\end{array}$} & \multirow[b]{2}{*}{$\begin{array}{l}\text { Genome } \\
\text { length }\end{array}$} & \multicolumn{3}{|c|}{ LCBs present in all taxa } & \multicolumn{2}{|c|}{$\begin{array}{l}\text { LCBs present in } \\
\text { subsets of taxa }\end{array}$} & \multirow[b]{2}{*}{ locality } \\
\hline & & & $\begin{array}{c}\text { bp } \\
\text { covered }\end{array}$ & $\begin{array}{c}\% \text { of } \\
\text { genome }\end{array}$ & $\begin{array}{l}\text { \# of } \\
\text { genes }\end{array}$ & $\begin{array}{c}\text { bp } \\
\text { covered }\end{array}$ & $\begin{array}{c}\text { \% of } \\
\text { genome }\end{array}$ & \\
\hline $\begin{array}{c}\text { Aeromonas hydrophila ATCC } \\
7966\end{array}$ & NC_008570 & $4,744,448$ & $1,132,632$ & 23.9 & 1,096 & $1,971,555$ & 41.6 & $\begin{array}{c}\text { Fresh and marine } \\
{[3]}\end{array}$ \\
\hline $\begin{array}{l}\text { Alteromonas macleodii deep } \\
\text { ecotype }\end{array}$ & NC_011138 & $4,412,282$ & $1,209,099$ & 27.4 & 1,223 & $1,607,063$ & 36.4 & $\begin{array}{c}\text { Mediterranean Sea } \\
{[4]}\end{array}$ \\
\hline Colwellia psychrerythraea $34 \mathrm{H}$ & NC_003910 & $5,373,180$ & $1,272,052$ & 23.7 & 1,279 & $2,130,197$ & 39.6 & Arctic sediments [5] \\
\hline Shewanella amazonensis SB2B & NC_008700 & $4,306,142$ & $1,312,077$ & 30.5 & 1,279 & $3,228,613$ & 79.4 & $\begin{array}{c}\text { Baltic Sea } 120 \mathrm{~m} \\
{[6]}\end{array}$ \\
\hline Shewanella baltica OS223 & NC_011663 & $5,145,902$ & $1,596,790$ & 31.0 & 1,504 & $4,924,714$ & 95.7 & $\begin{array}{c}\text { Baltic Sea } 240 \mathrm{~m} \\
{[7-9]}\end{array}$ \\
\hline Shewanella baltica OS155 & NC_009052 & $5,127,376$ & $1,515,912$ & 29.6 & 1,469 & $4,778,750$ & 93.2 & $\begin{array}{c}\text { Baltic Sea } 240 \mathrm{~m} \\
{[7-9]}\end{array}$ \\
\hline Shewanella baltica OS185 & NC_009665 & $5,229,686$ & $1,579,905$ & 30.2 & 1,511 & $4,997,928$ & 95.6 & $\begin{array}{c}\text { Baltic Sea } 240 \mathrm{~m} \\
{[7-9]}\end{array}$ \\
\hline Shewanella baltica OS195 & NC_009997 & $5,347,283$ & $1,572,889$ & 29.4 & 1,496 & $5,038,451$ & 94.2 & $\begin{array}{c}\text { Baltic Sea } 240 \mathrm{~m} \\
{[7-9]}\end{array}$ \\
\hline Shewanella denitrificans OS217 & NC_007954 & $4,545,906$ & $1,318,644$ & 29.0 & 1,244 & $2,749,058$ & 60.5 & Baltic Sea deep [10] \\
\hline $\begin{array}{c}\text { Shewanella frigidimarina } \\
\text { NCIMB } 400\end{array}$ & NC_008345 & $4,845,257$ & $1,306,074$ & 27.0 & 1,253 & $3,068,494$ & 63.3 & North Sea [11] \\
\hline $\begin{array}{c}\text { Shewanella halifaxensis HAW- } \\
\text { EB4 }\end{array}$ & NC_010334 & $5,226,917$ & $1,469,687$ & 28.1 & 1,407 & $4,727,461$ & 90.4 & Nova Scotia [12] \\
\hline Shewanella loihica PV-4 & NC_009092 & $4,602,594$ & $1,339,527$ & 29.1 & 1,306 & $3,377,749$ & 73.4 & Hawaii, USA [13] \\
\hline Shewanella oneidensis MR-1 & NC_004347 & $4,969,803$ & $1,525,080$ & 30.7 & 1,479 & $4,360,652$ & 87.7 & $\begin{array}{c}\text { Oneida Lake, USA } \\
{[14]}\end{array}$ \\
\hline $\begin{array}{c}\text { Shewanella pealeana ATCC } \\
700345\end{array}$ & NC_009901 & $5,174,581$ & $1,485,394$ & 28.7 & 1,424 & $4,573,456$ & 88.4 & Atlantic Ocean [15] \\
\hline Shewanella piezotolerans WP3 & NC_011566 & $5,396,476$ & $1,485,147$ & 27.5 & 1,482 & $4,252,921$ & 78.8 & Pacific Ocean [16] \\
\hline Shewanella putrefaciens CN-32 & NC_009438 & $4,659,220$ & $1,596,811$ & 34.3 & 1,559 & $4,351,757$ & 93.4 & $\begin{array}{l}\text { Fresh and marine } \\
{[1,17]}\end{array}$ \\
\hline Shewanella sediminis HAW-EB3 & NC_009831 & $5,517,674$ & $1,477,164$ & 26.8 & 1,391 & $4,444,654$ & 80.6 & Nova Scotia [18] \\
\hline Shewanella sp. ANA-3 & NC_008577 & $4,972,204$ & $1,494,516$ & 30.1 & 1,394 & $4,647,695$ & 93.5 & $\begin{array}{c}\text { Woods Hole, USA } \\
{[19]}\end{array}$ \\
\hline Shewanella sp. MR-7 & NC_008322 & $4,792,610$ & $1,478,293$ & 30.8 & 1,392 & $4,564,063$ & 95.2 & Black Sea [14] \\
\hline Shewanella sp. MR-4 & NC_008321 & $4,706,287$ & $1,478,804$ & 31.4 & 1,499 & $4,567,658$ & 97.1 & Black Sea [14] \\
\hline Shewanella sp. W3-18-1 & NC_008750 & $4,708,380$ & $1,578,878$ & 33.5 & 1,517 & $4,443,111$ & 94.4 & Coastal Pacific [20] \\
\hline $\begin{array}{c}\text { Shewanella woodyi ATCC } \\
51908\end{array}$ & NC_010506 & $5,935,403$ & $1,503,207$ & 25.3 & 1,476 & $4,442,801$ & 74.9 & $\begin{array}{c}\text { Mediterranean Sea } \\
{[21]}\end{array}$ \\
\hline \# of LCBS & & & 243 & & & 3,004 & & \\
\hline alignment length & & & $3,361,015$ & & & $12,456,624$ & & \\
\hline
\end{tabular}

of its species to convert heavy metals and toxic substances (e.g. iron, sulfur, uranium) into less toxic products by using them as electron acceptors in certain respiratory situations, making them of interest for environmental clean-up (e.g. iron, sulfur: [22]; uranium: [23]). To this end, 19 genomes have been fully sequenced and deposited on GenBank as of 2009. Annotations suggest that species possess approximately 5,000 genes and have genomes of approximately $5 \mathrm{Mbp}$ (details in Table 1).

The goal of the study presented here is to investigate how we can use whole genome data, not only to build a tree but to inform us of gene and genome history by comparing the hypothesis of historical homology supported by the phylogenetic hypothesis to what is known about gene function. There is a computational interest in the ability to build large trees, both in number of taxa and number of characters, e.g. [24,25]. The biological history of genes and genomes can be investigated based on the taxomonic history of the bearers of these characters. This goes further than just the prediction of function of uncharacterized genes, but also includes the potential to track changing function over gene history and finding up- or down-stream segments of co-evolving DNA. Eisen and Fraser highlighted many of these 
goals when they introduced the term "phylogenomics" [26]. While these goals are broad and ambitious, it is the hope that the present study represents a step in this direction.

The presented approach also represents a shift for phylogenetic systematics, in which historically one has generally known all the characters of interest very well and perhaps had a well-formed opinion about their history based on a lifetime of knowledge about their distribution and subtle variations. Even with molecular characters in the form of one or a few genes, even with many taxa, one gets to know the 'reliable' parts of an alignment and often memorizes the DNA sequence after having sequenced and edited the same marker for several years. The approach presented here proposes a new perspective which is obligated by the new kinds of data being gathered, particularly those from next-generation and shotgun sequencing, which generate millions of nucleotide base-pairs (bp) as opposed to thousands. Primary homology (sensu dePinna, [27]) must be determined in an automated fashion given the vast amount of data and the few character states of nucleotide data. The phylogenetic tree becomes an intermediate point it is built based on hypotheses of primary homology, which it tests, and then is used as a framework for optimizing the character states and looking back to functional gene annotations to begin to answer questions about gene and genome history. Polymerase chain reaction (PCR) primers can provide hypotheses of primary homology, as amplifications using primers target conserved flanking regions, which provide a sufficient level of confidence that the 'same' regions are being sequenced. With next-generation sequencing, we have no such sense of location (particularly with bacteria), as we expect rearrangement of genes or other genomic segments over evolutionary history [28-31]. Annotations can provide information about the function of genes and the location of open reading frames, but these may not lead us to historical homology and will miss much of the homology present in the genome, for example among genes of altered function or non-coding DNA.

A second goal of this study is to present an example of comparative genomics for a closely related taxon that is densely sampled. This helps to avoid some of the downsides of comparative genomics when few, disparate taxa are compared: leaps of faith with character homology and trivial phylogenetic topologies. Finally, as an attempt to begin the investigation of gene history, $16 \mathrm{~S}$ rRNA is presented as a test case. 16S rRNA was chosen because it is the marker that has defined prokaryote taxonomy for the past 30 years [32]. While it is not used without some skepticism, e.g. [33,34], the way that primary homology is generated here provides an opportunity to test our assumptions about $16 \mathrm{~S}$ rRNA. This manuscript will address the outlined points in the following sections: Mauve primary homology [35], genome trees, subset trees, and 16S rRNA investigation.

\section{Methods}

For all taxa of Shewanella for which the genome sequence has been completed and deposited on GenBank, 16 species and 3 additional strains of one species and for three outgroup taxa, unannotated genome sequences were downloaded (strain and accession numbers in Table 1). Seven gene loci were also downloaded individually for all 22 taxa from the same genome accession numbers. The genes are gyrB (DNA gyrase subunit B), rpoA (DNA directed RNA polymerase subunit alpha), recA (recombinase A), topA (DNA topoisomerase I), $m r e B$ (rod shape-determining protein), gapA (glyceraldehyde-3-phosphate dehydrogenase), and atpA (ATP synthase F1 subunit alpha). Those species for which only one strain is included will hereafter be referred to by only their species name. For Shewanella baltica, for which multiple strains have been sampled, I will refer to the strain numbers throughout. Annotations were also downloaded from RefSeq (GenBank's Reference Sequence Collection, 2009). The sampled genomes range in size from 4,306,142 nucleotide base-pairs (bp) and 3,785 genes (Shewanella amazonensis) to 5,935,403 bp and 5,096 genes (Shewanella woodyi). All of the below analyses were performed on a $2.8 \mathrm{GHz}$ QuadCore MacPro with 20 GB RAM.

\section{Mauve primary homology}

Sequences were submitted to a genome alignment using Progressive Mauve [35]. This program has been used previously on fairly closely related members of Gammaproteobacteria [36]. Traditional multiple sequence alignment cannot be used on complete genome sequences because significant rearrangement of genes or fragments has been shown to occur over evolutionary history [28-31]. Mauve addresses this issue by finding locally collinear blocks (LCBs), or contiguous segments of sequence within which there has not been rearrangement, but within a longer sequence that may have been subject to rearrangement events. The default parameters in Mauve were used. Mauve finds anchor points of similarity and then extends these matches outward. A single LCB becomes two when a sequence segment is found somewhere else in the genome for one of the taxa, meaning that a rearrangement has occurred. Mauve does not allow one sequence fragment to be homologous to more than one fragment in another species. CGView [37] has been used to plot the genomic location of LCBs found common to all species and to project gene annotations onto LCB alignments. Resulting LCBs were submitted to standard multiple sequence 
alignment with MAFFT [38]. Mauve output XMFA files include the base-pair ranges (e.g. bp 1-10,000) of each LCB for each taxon. The base-pair locations were used along with annotations to assess which genes were present in each LCB. At the suggestion of a reviewer, Mauve was also run with a single outgroup taxon, $C$. psychrerythraea, to compare the influence of one vs. more than one outgroup on the percent of the genome covered by the Mauve alignment.

\section{Genome trees}

Aligned LCBs were concatenated and submitted for phylogenetic analysis with parsimony in TNT [39], maximum likelihood in RaxML v. 7.0.4 [40], and Neighbor Joining [41] in Geneious Pro 4.8.3 [42]. Long alignments are challenging for phylogenetic tree building programs as many of these programs have a limit on the number of input characters or cannot access enough RAM to read the alignment. Those programs mentioned above were able to read the data analyzed here. The TNT commands consisted of 1000 builds with SPR and TBR followed by 1500 replicates of ratchet and tree fusing $[43,44]$. RaxML was run under the GTRGAMMA model of nucleotide substitution. Only a single bootstrap replicate was attempted at a time, as this seemed to be the computational limit, at least for the used workstation, as any additional searching caused an error. Neighbor Joining was run with Jukes-Cantor, Tamura-Nei, and HKY genetic distance models in three separate analyses. Bootstrap resampling was attempted in TNT, with 5,000 pseudoreplicates. As an additional measure of support, trees were built from individual LCBs and were used to score whether nodes in the genome tree were also present in the individual LCB trees. Gaps were initially treated as a fifth state in TNT but all genome-wide data-sets were also reanalyzed with gaps treated as missing data. When not specified, the TNT analyses refer to those in which gaps were treated as a fifth state.

\section{Subset trees}

In order to compare the phylogenetic signal from the entire genome to signals from subsets of the genome, three courses of action were taken. The first asks the question whether localized signal is congruent with whole genome signal. To this end, phylogenetic hypotheses were built for individual LCBs, as above, in TNT. Second, in order to address whether the number of characters has a direct result on the topology, scripts using BioPerl were used to randomly sub-sample the nucleotide alignment and produce data-sets of varying size, 20,000 bp, 100,000 bp, 500,000 bp and 1,000,000 $\mathrm{bp}$, which were submitted to the same phylogenetic treatment as above. Finally, a seven-gene analysis was attempted in TNT, as above, to compare a traditional phylogenetic analysis to the genome-level analysis that was the main goal of the study.

\section{S rRNA investigation}

$16 S$ rRNA copies were tracked throughout the Mauve LCBs in order to establish for which of the $16 \mathrm{~S}$ rRNA copies Mauve made an hypothesis of homology. All copies of $16 \mathrm{~S}$ rRNA for all taxa (taxa have 8-11 copies each, according to annotations, for a total of 200 terminal branches for the 22 taxa), whether or not present in an LCB, were extracted from their respective annotated genome files, aligned with MAFFT, and submitted for phylogenetic analysis in TNT and RaxML, as above.

\section{Results}

\section{Mauve primary homology}

Mauve results are summarized in Table 1. Figure 1 is a CGView plot, which shows the genomic locations of those LCBs present for all taxa. Each circle represents a taxon (genome) and the colored blocks represent the individual LCBs. Blocks of the same color are putatively homologous LCBs. White space represents the parts of the genome within which Mauve did not find homology among all taxa sampled. Mauve ran for approximately 7 days and 243 LCBs were found common to all taxa. The length of individual LCBs after DNA sequence alignment ranged from 645 bp to 129,020 bp and the number of genes per LCB ranged from zero to 30 and the mean was 6.07 genes per LCB for S. woodyi, for example. When added together, these 243 all-taxa LCBs represented a range from 23.7 to $34.3 \%$ of the genomes and 1096 and 1559 genes (as per annotations from RefSeq) along with non-coding DNA (Table 1). For $S$. sp. $M R-7$, for example, there are 218,403 non-coding nucleotide base-pairs included, $14.8 \%$ of the unaligned nucleotide base-pairs. The concatenated alignment was $3,361,015 \mathrm{bp}$ (hereafter referred to as the $3 \mathrm{Mbp}$ alignment). The sequence identity of the alignment is $48.7 \%$. If we also consider those LCBs shared among subsets of taxa (at least 2) that contained $>100 \mathrm{bp}$, there were 3004 LCBs, which represented 36.4 to $97.1 \%$ of the genomes (Table 1). The concatenated alignment of these 3004 LCBs was $12,456,624$ bp (hereafter referred to as the $12 \mathrm{Mbp}$ alignment). When the only outgroup taxon considered is C. psychrerythraea, there were $325 \mathrm{LCBs}$ and the concatenated alignment was 4,604,291 bp. C. psychrerythraea had 1,690,088 unaligned bp present in the Mauve alignment when it was the only outgroup, as compared to $1,272,052$, when the other two outgroups were also included.

\section{Genome trees}

For the $3 \mathrm{Mbp}$ alignment, that was based on the 243 alltaxa LCBs, the TNT (gaps as fifth state) and RaxML 


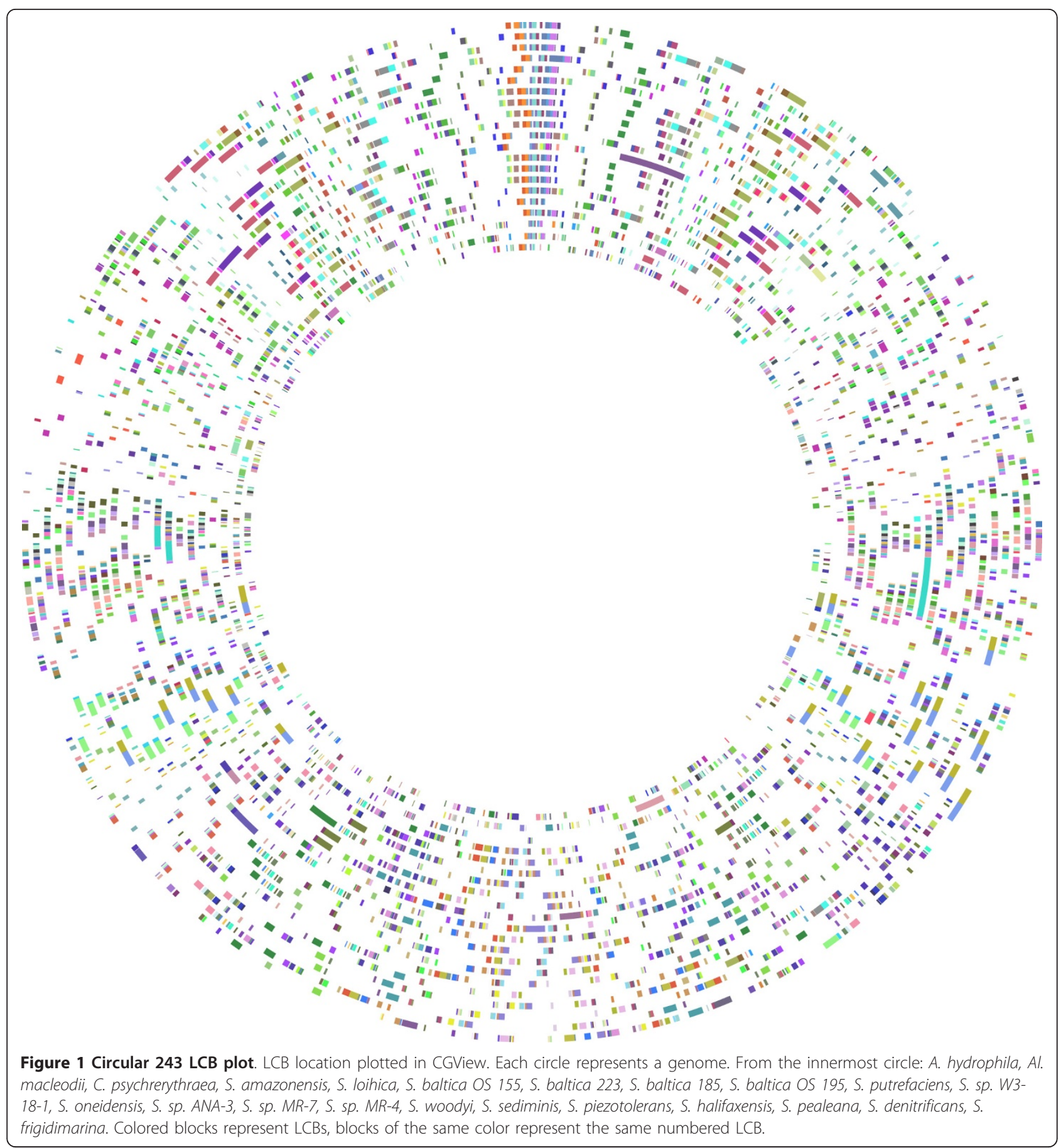

trees have the same topology (shown in Figure 2 - hereafter referred to as the 'genome tree'), while the NJ tree does not (Figure 3A). The only reason NJ was attempted was to investigate the idea that when there are so many data, phylogenetic hypotheses might converge on those constructed from similarity only. In this case, the topologies are not the same. All three NJ genetic distance models produced the same topology. The TNT tree for the $3 \mathrm{Mbp}$ alignment had 7,875,803 steps. Multiple individual RaxML runs all produced the same topology. The likelihood score was -860351.367382. The $12 \mathrm{Mbp}$ alignment and $3 \mathrm{Mbp}$ alignment gave the same topology in TNT, which is not unexpected given that the $3 \mathrm{Mbp}$ alignment is just a subset of the $12 \mathrm{Mbp}$ alignment. The $12 \mathrm{Mbp}$ alignment produced a tree of 29,512,322 steps in TNT but a tree was not found in RaxML; the 


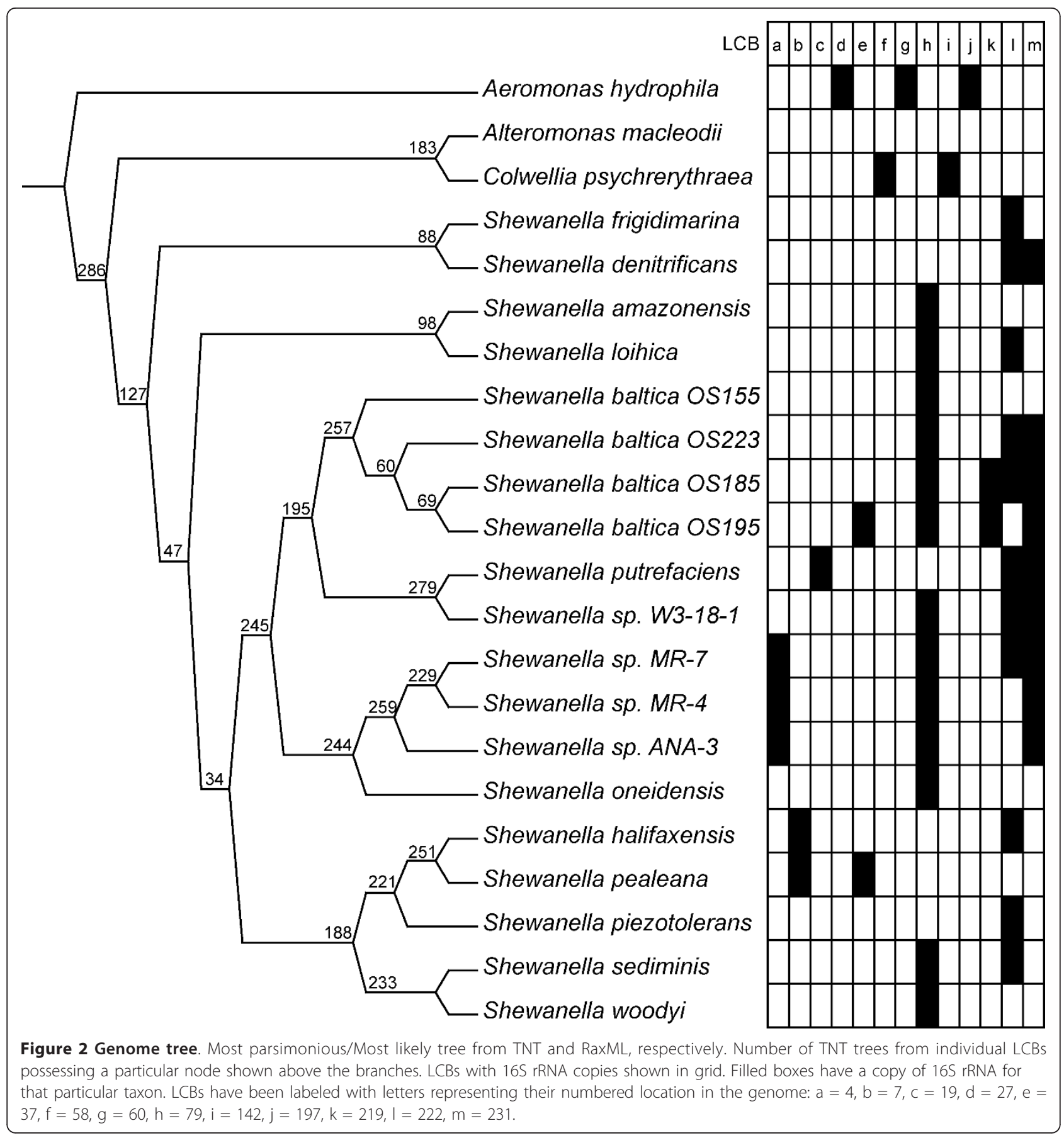

program terminated with an error. The NJ trees for the 12 Mbp alignment had the same topology as the NJ trees for the $3 \mathrm{Mbp}$ alignment (Figure 3A). When gaps are treated as missing data for the $3 \mathrm{Mbp}$ alignment in TNT (Figure 3C), S. amazonensis and S. loihica are no longer sister, and the placement of $S$. denitrificans $+S$. frigidimarina is much more derived. This tree had 4,274,327 steps. Shewanella formed a monophyletic group in every case, however. Bootstrap values from
TNT are not shown for the genome tree, as they are $100 \%$ for every node. Above the branches in Figure 2 is the number of trees built from the 243 individual LCBs (from the $3 \mathrm{Mbp}$ alignment) that contain that particular node present in the genome tree. The analysis in which C. psychrerythraea is the only outgroup taxon included is shown in Figure 3D. The most parsimonious tree had a length of 10,573,382 when gaps are treated as a fifth state. The same topology resulted when gaps were 


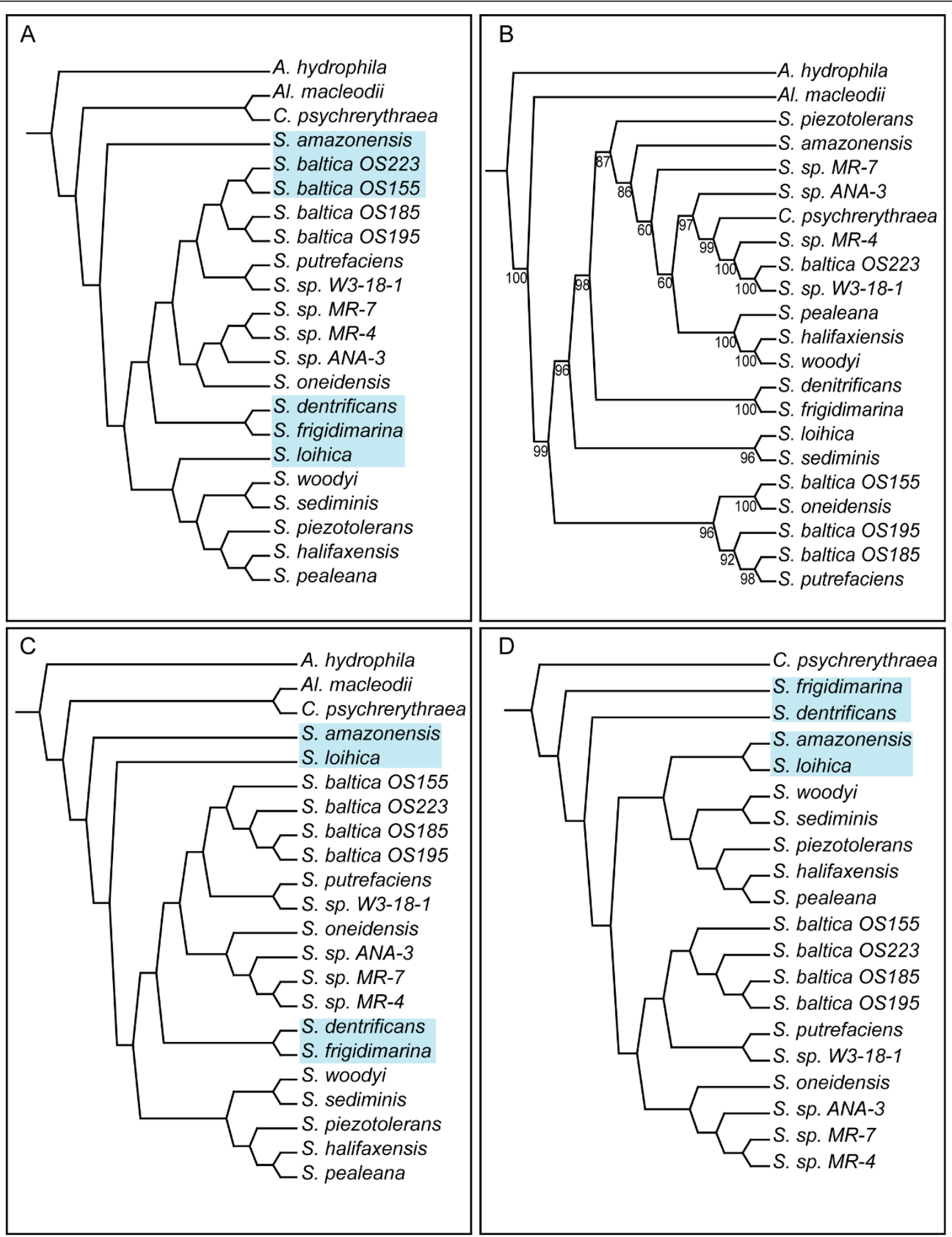

Figure 3 Neighbor Joining, seven-gene, gaps-as-missing, and single-outgroup trees. A: Neighbor Joining topology for both 3 Mbp and 12 Mbp alignments; B: Most parsimonious tree from TNT based on seven gene loci, with boopstrap resampling frequencies below the branches; C: Most parsimonious tree from TNT when gaps in $3 \mathrm{Mbp}$ alignment are treated as missing; D: Most parsimonious tree from TNT when C. psychrerythraea is the only outgroup taxon. Taxa with variable placement are highlighted to show topology differences in A, C, and D. 
treated as missing, but the tree cost was 5,753,742 steps. Trees have been deposited in TreeBASE and may be accessed at http://purl.org/phylo/treebase/phylows/ study/TB2:S11219.

\section{Subset trees}

On the trees built from the 243 individual LCBs in TNT, for which there were 286 most parsimonious trees (MPTs), none had the topology of the genome tree with gaps as fifth state. There are 285 unique topologies represented in these 286 trees. None of these 286 trees has the topology of the gaps as missing TNT analysis either. While the individual LCB trees cannot be referred to as gene trees per se, as the vast majority of LCBs contain more than one gene as well as non-coding DNA, the phenomenon of parts of a data-set not producing the same phylogenetic signal, is comparable. To address whether it was an issue of number of base-pairs versus different localized signals concentrated in different contiguous parts of the genome (i.e. each LCB), I used the data-sets generated with BioPerl scripts, that randomly selected nucleotide columns from the $3 \mathrm{Mbp}$ alignment and separately for the $12 \mathrm{Mbp}$ alignment. These data-sets consisted of 20,000 bp, 100,000 bp, $500,000 \mathrm{bp}$ and 1,000,000 bp for each of the original alignments. When I performed phylogenetic analyses on these data-sets, all produced the same topology as the phylogenetic (TNT and RaxML) genome tree; the same topology that was not found for any of the 243 singleLCB data-sets. For the seven-gene dataset, genes were aligned separately in MAFFT and then concatenated, resulting in an alignment of 13,009 bp. The topology resulting from this analysis is shown in Figure 3B with bootstrap resampling frequencies shown below the branches.

\section{S rRNA investigation}

The next step was to associate the annotation, or list of open reading frames (ORFs) and their locations, with the list of LCB boundaries for each species. Of initial interest was tracking the multiple copies of $16 \mathrm{~S}$ rRNA within these taxa and assessing their presence within the LCBs. There were 13 LCBs that contained a copy of $16 \mathrm{~S}$ rRNA for at least one species. These are shown in the grid next to the tree in Figure 2. The LCBs are 4 (S. $s p$. MR-7, S. sp. MR-4, S. sp. ANA-3), 7 (S. halifaxensis, S. pealeana), 19 (S. putrefaciens), 27 (A. hydrophila), 37 (S. baltica OS195), 58 (C. psychrerythraea), 60 (A. hydrophila), 79 (S. amazonensis, S. loihica, S. baltica OS155, S. baltica OS223, S. baltica OS 185, S. baltica OS195, S. sp. W3-18-1, S. sp. MR-7, S. sp. MR-4, S. sp. ANA-3, S. oneidensis, S. sediminis, S. woodyi), 142 (C. psychrerythraea), 197 (A. hydrophila), 219 (S. baltica OS185, S. baltica OS195), 222 (S. frigidimarina, S. denitrificans, S. loihica, S. baltica OS223, S. baltica OS185, S. putrefaciens, S. sp. W3-18-1, S. sp. MR-7, S. halifaxensis, S. piezotolerans, S. sediminis), 231 (S. denitrificans, S. baltica OS223, S. baltica OS185, S. baltica OS195, S. putrefaciens, S. sp. W3-18-1, S. sp. MR-7, S. sp. MR-4, S. sp. $A N A-3)$. The first obvious pattern is that, while all copies of $16 \mathrm{~S}$ rRNA are homologous (derived from a single 16S rRNA ancestral copy), there was no single copy of 16S rRNA aligned by Mauve across all taxa, which would indicate the possibility of orthology. When the LCBs present in subsets of taxa were considered, and the subset of interest is all Shewanella species, there was also no single $16 \mathrm{~S}$ rRNA copy aligned across all Shewanella taxa. It must also be noted that it is possible that there is a single orthologous copy that Mauve is unable to recover.

When all 16S rRNA copies were extracted from annotated genomes and subjected to multiple sequence alignment and phylogenetic analysis, for a number of species, two $16 \mathrm{~S}$ rRNA copies within a particular taxon were identical, but there were never any copies identical among different species. For S. baltica strains, however, there were instances where one strain had a copy identical to a copy in another strain. The results of the phylogenetic analysis of all copies of $16 \mathrm{~S}$ rRNA were, from TNT, a MPT with 1275 steps (Figure 4). Out of the 1584 characters, 338 were parsimony informative. Topological differences between the TNT tree and that produced by RaxML will be addressed in the discussion.

\section{Discussion \\ Mauve primary homology}

The approach Mauve takes to assigning primary homology does not take function, gene boundaries, or ORFs into account a priori. Mauve allows each sequence fragment to be homologous to only one other fragment. Also, when we consider only the LCBs present in all taxa, we avoid fragments that might be recently laterally transferred, because these would not be present in all taxa. Since Mauve does not consider annotation a priori, one can compare the Mauve alignment to annotation without following circular reasoning to ascertain which genes are aligned to one another (putative gene homologies). Questions or hypotheses about probable function for unknown genes and history of regions of conflicting function can now be studied. Figure 5 illustrates this approach. For LCB 27, which consists of 13,022 aligned nucleotide base-pairs, the gene annotations have been projected onto the alignment. What is obvious from this plot is that in general, the gene boundaries match up well and the gene content of LCB 27 is fairly consistent across the taxa sampled. But there are areas of interest, for example rpmD (or $50 \mathrm{~S}$ ribosomal protein L30) is present in most taxa, but absent in $S$. sediminis, filled 




Figure 4 Tree of all copies of 16S rRNA. Monophyletic clades and colored; paraphyletic and polyphyletic clades are black. Circles below the branches indicate topological congruence with the genome tree. Stars above branches indicate bootstrap resampling frequencies above $75 \%$. instead by non-coding DNA. This pattern is consistent with multiple possible explanations, including (1) poor annotation, (2) sequencing error, (3) this gene has become inactivated or degraded significantly enough that it is not recognized by annotation, or (4) this gene has really been deleted from the genome. Furthermore, the length variation in particular genes is put into context and we can see perhaps from what kind of material (non-coding or gene) they have been transformed. The length variation might not only indicate de novo insertions of material, but conversion from a neighboring gene. This possibility is illustrated in $r p s E$ and $r p m D$, where rpmD spills into rpsE for two $S$. baltica strains (Figure 5).

The allowance for variation within an LCB for basepair length and number of genes among different taxa is how the estimates of primary homology considered by Mauve differ from previous studies: they do not require that a gene, which might look functionally the same, be homologous (aligned) across all taxa simply because it is present in these taxa. This is key in our beginning to understand gene histories and how these histories interact with the functional roles of genes. The homologies among fragments of non-coding DNA are also important, because if these kinds of analyses are extended to eukaryotes, which have vastly more non-coding DNA, we will be looking for ways to include these data and not be limited to evidence of history only from genes, which might have conflicting histories.

As can be seen in Table 1 in the all-taxa LCB dataset, the coverage by LCBs among included taxa ranges between $23-34 \%$. In the subset taxa LCB data-set, one can track the coverage by phylogenetic position, with the innermost nodes having the most complete coverage. This coverage (Subset taxa LCBs) ranges from 36$97 \%$. Outgroup taxa have a lower percentage of their genome covered by LCBs than do ingroup taxa. This pattern would be expected if the outgroups are indeed more distant relatives than any of the ingroup taxa. The inclusion of outgroups in a Mauve analysis decreases the LCB coverage, because they are more distantly related, but is essential to polarizing the characters obtaining the optimal phylogenetic topology. The reason three outgroup taxa were included was because there had not been a previous study showing that Alteromonas and Colwellia were indeed basal to Shewanella. One could not assume that Shewanella was monophyletic a priori; the seven-gene analysis (Figure 3B) finds a non-monophyletic Shewanella. To address a reviewer comment that using a single outgroup would increase the amount of data considered in the phylogenetic 


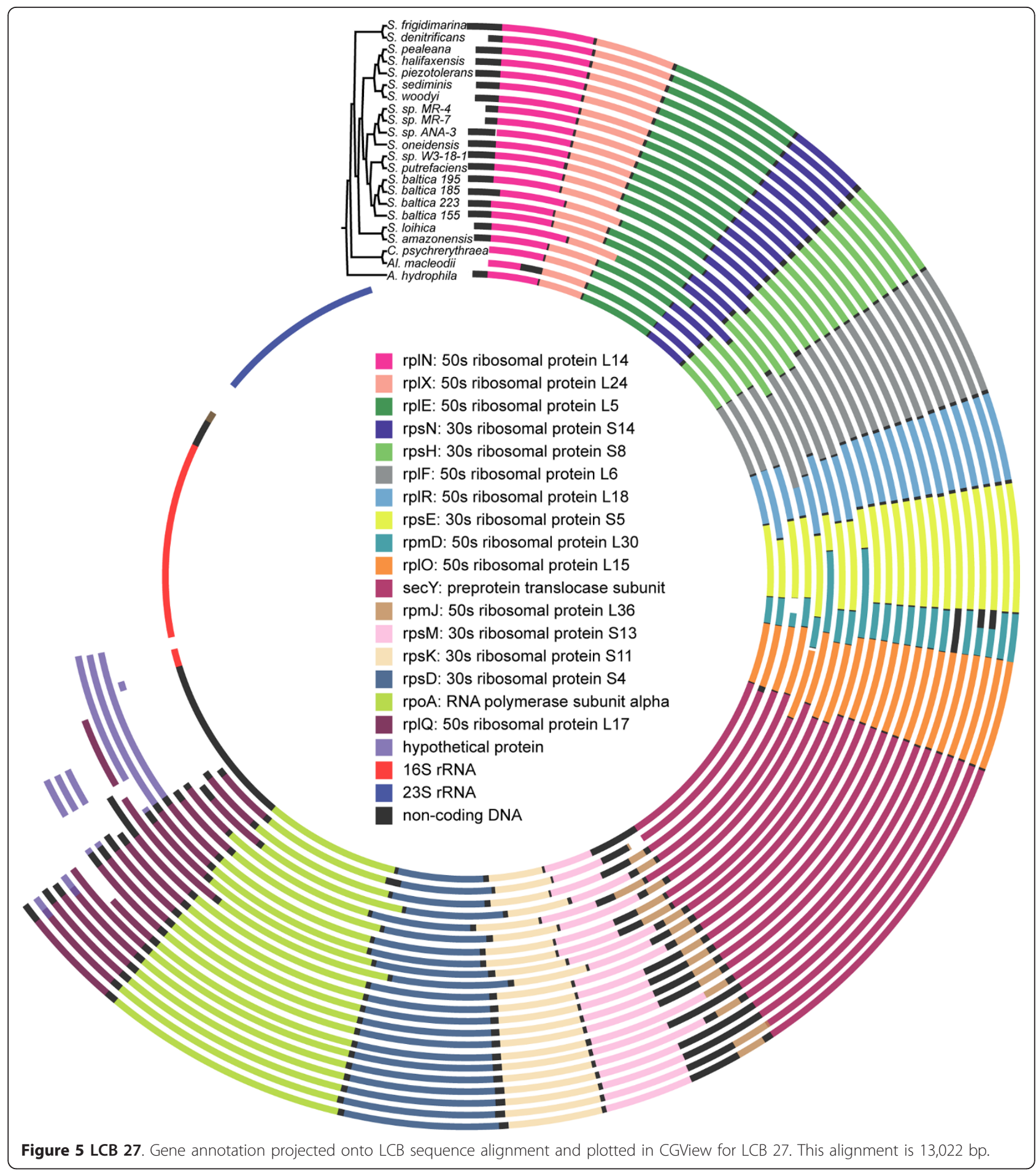

analysis, however, another Mauve run was attempted with a single outgroup (C. psychrerythraea). This species was chosen because it was found to be the most closely related to Shewanella, and therefore would cause the greatest increase in data if the other outgroups were not included. If just the most basal outgroup was included, one would not expect much of a change in genome coverage. The initial analysis, in which all three outgroup taxa are included, allows one to make the most a posteriori claims about homology for the broadest range of taxa. The topological differences are discussed below. 


\section{Genome trees}

The number of parsimony informative characters in the $3 \mathrm{Mbp}$ alignment (26.48\%) was within the range of many molecular studies based on one or a few genes, e. g. $[45,46]$. This fact provides a sense of confidence that Mauve was finding real, or at least likely, homologies. This percentage ranged from $1.4 \%$ to $53.6 \%$ when LCBs were compared to each other. If the percentage of parsimony informative characters had been significantly higher, I might be concerned that non-homologous and non-similar sequences were being aligned. In the RaxML analysis, gaps were treated as missing. Gaps were treated as a fifth state as the default for the parsimony (TNT) analyses because gaps do represent evolutionary events. The nature of the Mauve analysis, in my opinion, lends itself to the treatment of gaps as fifthstate characters because Mauve either breaks up a single LCB into two or more if homologous fragments are found in different positions in one or more genomes. If Mauve has postulated one LCB instead of two, it is then assumed that gaps represent the lack of homologous DNA sequence, not missing data. As for statistical support, values of $100 \%$ on all nodes are not particularly telling. By scoring the individual LCB trees for nodes present in the genome tree, it is clearer which nodes are the most and least robust. The relationships among strains of $S$. baltica have low support (60/286 trees), as might be expected if these have either recently diverged, or are exchanging genes. Confidence in the topology is also supported by the results of the random data-set analyses, which amount to a jackknife technique (without replacement).

When gaps are treated as missing data, as well as when $C$. psychrerythraea is the only outgroup taxon considered, there are topological differences in the placement of S. amazonensis, S. loihica, S. denitrificans, and $S$. frigidimarina, although $S$. denitrificans and S. frigidimarina are always sister. The remaining taxa retain their relationships. The node that separates $S$. denitrificans, S. frigidimarina, S. amazonensis, and S. loihica from the remaining species of Shewanella is the least well supported node in the tree, with 34 out of 286 individual LCB trees containing that node, indicating that it is not surprising that these four taxa are the ones that are placed differently in the various permutations of genome-wide data-sets. It is interesting that the RaxML tree and the gaps as fifth-state TNT tree have the same topology. There are multiple possible explanations for this finding. A reviewer mentioned that if genes are lost or gained in a single step, that considering gaps individually dramatically over-emphasizes the number of evolutionary events. It is also important to note, however, that by treating gaps as missing, one is ignoring those evolutionary events completely. It could be that a significant proportion of the evidence is lost in the gaps as missing analyses, but that maximum likelihood is better at compensating for multiple hits. To address the possibility that gaps, representing insertion/deletion (indel) events are overwhelming the phylogenetic signal, the number of parsimony tree steps resulting from indel events at internal nodes has been calculated to be 814,304 . This number is $23.6 \%$ of all indels (the rest being at the terminal branches, autapomorphies that provide no information on branching pattern in parsimony) and $10.3 \%$ of total tree length. These calculations show that information from gaps does not make up a dominant proportion of the phylogenetic signal. It is entirely possible that the lack of indel data in the parsimony-missing data analyses leads to a different answer, but the presence of indel data in the gaps as fifth-state analysis and the ability of maximum likelihood to account for saturation give the same tree. This just argues for evidence that the genome tree (RaxML, parsimony gaps as fifth state) is the optimal tree.

For 22 taxa, there are $1.31 \times 10^{\wedge} 25$ possible rooted bifurcating trees [47]. It is surprising, then, that there was an immediate convergence on the optimal topology for the $12 \mathrm{Mbp}, 3 \mathrm{Mbp}$, and random data-sets when run in TNT. Wagner tree build plus TBR branch swapping found the optimal tree very rapidly, within a minute. No amount of ratcheting or tree fusing altered the topology or tree length. The decisiveness of these data [48] marks the difference between analyses consisting of one or a few genes and the present analysis. Just as the idea of support needs to be adjusted to accommodate whole genome analyses, so do our expectations of tree search.

A recent paper considering the systems biology of Shewanella based on the whole genome sequences of 10 taxa (a subset of those included here) produced a phylogeny for those 10 taxa based on 1507 single-copy orthologs identified through a combination of, "(i) proteinprotein pairwise reciprocal BLAST (blastp); (ii) reciprocal protein genomic sequence best match (tblastn); and (iii) Darwin pairwise best hit" ([49], p. 15914). Their tree had the same topological relationships for those 10 taxa as the genome tree presented here. It is also interesting that the number of genes found to be single-copy orthologs in [49] is comparable to the number of genes present in the LCBs for the ingroup taxa presented here (Table 1). Future work might ask whether the sets of orthologs are similar for these two data-sets and how these two different approaches (ortholog identification vs. unannotated homology detection) might complement each other to best utilize whole genome sequence data.

\section{Subset trees}

It is interesting that none of the trees that resulted from analysis of each LCB separately produced the same 
topology as the genome tree, even though there are relatively few taxa, and that the randomly sampled data-sets all produced the genome-tree topology, even though some of the LCBs were longer than some of the randomly sampled data-sets. Sometimes Shewanella was not monophyletic in individual LCB trees. What the results highlight, is that with a genome approach, which does not only focus on particular genes of interest, one is able to discern a unique phylogenetic signal. The random data-set tree results demonstrate that localized LCB signal might be a factor, even when an LCB contains 25 or more genes. One might expect that sampling nucleotides across all LCBs produces a signal closer to the optimum than does focusing on parts of the genome with putatively different histories. The surprising insight here was that 20,000 bp was enough to see this effect, for the present taxon sampling. It should also be noted that Mauve provides a kind of filter, in that the LCBs consist of those parts of the genome that have passed tests of similarity and co-linearity. The $3 \mathrm{Mbp}$ data-set, based on LCBs common to all taxa, represents a very complete, ideal data-set; approximately one-third of the genome (spread over the whole genome; Figure 1) for which all taxa have data. This is perhaps part of the reason that $20,000 \mathrm{bp}$ is enough to recover the genome tree topology, in this case. As suggested by a reviewer, the possibility exists that 20,000 bp is simply enough for the model mis-specification artifacts caused by mixedtree signals or incorrect substitution models to consistently yield an incorrect topology. This explanation would require, however, that all LCBs, or all LCBs except one also had this problem because they all produce different topologies that are not congruent with the genome tree.

For the seven-gene tree (Figure 3B), there is generally high bootstrap support, but there are only two ingroup taxa that retain the same sister-group relationships that are also present in the genome tree (Figure 2). The genes chosen for the analysis were the same (minus $16 \mathrm{~S}$ rRNA) as those chosen for a phylogenetic analysis for Vibrionaceae, the most closely related family to Shewanellaceae [46]. Even the four S. baltica strains appear scattered across the tree. The two large clades, which are consistent across all other trees, containing (S. woodyi, S. sediminis, S. piezotolerans, S. halifaxensis, and $S$. pealeana) and (S. baltica, S. putrefaciens, S. sp. W3-181, S. sp. MR-4, S. sp. MR-7, S. sp. ANA-3, and S. oneidensis) are not present in the seven-gene tree. C. psychrerythraea, a putative outgroup taxon is nested deeply within the ingroup in the seven-gene tree.

\section{S rRNA investigation}

The fact that Mauve does not generate a hypothesis of positional homology for any single copy of $16 \mathrm{~S}$ rRNA even though all copies are very similar speaks to the challenges that occur when dealing with multiple gene copies. The pattern of gene arrangement flanking instances of $16 \mathrm{~S}$ rRNA is not enough to assign a hypothesis of positional homology. There is simply too much rearrangement to have confidence in such a hypothesis. The taxonomic relationships suggested by the all-copy 16S rRNA tree from TNT (Figure 4) are different than those suggested by the genome tree (Figure 2). Nodes of congruence are highlighted in Figure 4. There are many similarities between the all-copy $16 \mathrm{~S}$ rRNA tree and the genome tree, however: Shewanella is monophyletic, S. sp. MR-7, S. sp. MR-4, S. oneidensis, S. sp. ANA-3 are monophyletic, S. halifaxensis and S. pealeana are sister, $S$. denitrificans and $S$. frigidimarina are sister, S. sp. W3-18-1 and S. putrefaciens form a clade, $S$. piezotolerans, S. halifaxensis and S. pealeana form a clade, S. sediminis and S. woodyi are sister, Al. macleodii and $C$. psychrerythraea are sister. The $16 \mathrm{~S}$ rRNA copy tree from RaxML shared many nodes in common with the $16 \mathrm{~S}$ rRNA tree from TNT, but found the $A l$. macleodii and C. psychrerythraea clade within Shewanella and did not find $S$. denitrificans and S. frigidimarina as sister. The fact that the TNT and RaxML trees are not completely congruent is not particularly surprising given that there are few parsimony informative characters in 16S rRNA and that there is no expectation that a tree-like branching pattern exist for these gene copies. For the TNT run, the gaps were treated as a fifth state, so that a gap can be informative. RaxML treats gaps as missing data, so that might also account for the differences.

Haggerty et al., [50] constructed a similar 16S rRNA copy tree, but did so for 17 species across four genera: Escherichia, Shigella, Yersinia, and Salmonella (also Gammaproteobacteria). They found the backbone of this tree, i.e. the separation of genera, conforming to their taxonomic expectations. They did not find widespread monophyly of copies at the species level, however. The tree shown in Figure 4, based on the present analysis, does show monophyly for many species. The following taxa formed monophyletic groups of $16 \mathrm{~S}$ rRNA copies: C. psychrerythraea, Al. macleodii, S. loihica, S. woodyi, S. sediminis, S. pealeana, S. amazonensis, S. putrefaciens, S. oneidensis, S. sp. ANA-3, S. denitrificans, S. frigidimarina. These taxa formed paraphyletic groups: S. halifaxensis (S. pealeana nested inside), S. sp. W3-18-1 (S. putrefaciens nested inside). The following taxa had gene copies scattered among those of other taxa, S. sp. MR-7, S. sp. MR-4, S. baltica OS155, S. baltica OS185, S. baltica OS195, S. baltica OS223.

There is no expectation that this is the actual evolutionary history of these gene copies, or that it should 
provide the correct relationships among taxa, because multiple gene copies cannot all be orthologous to one another, and are homologous only at the level that there was one initial copy of $16 \mathrm{~S}$ rRNA, but that is not informative at this phylogenetic level of inquiry. It was merely an exercise to see if the copies from one species group more closely with the other copies for that species or with copies from another species. The former is most often the case. The notable exceptions are the $S$. baltica strains, which are classified as strains of the same species and the S. sp. MR-4 and S. sp. MR-7. S. sp. MR-4 and MR-7 were isolated from different depths of the Black Sea [14]. It follows that these may have been separate lineages for a much shorter period of time than the other taxa included in the analysis, or that there continues to be gene exchange. The major pattern, that of monophyly of within-species copies, might be explained in multiple ways. Haggerty et al., 2009 suggest that such a pattern might reflect "homogenization" of $16 \mathrm{~S}$ rRNA copies such that each species has its own unique suite of copies of the gene. This is also known as concerted evolution [51]. The question remains as to why Haggerty et al., 2009 do not recover a concerted evolution type pattern, even though they consider taxa not so distantly related to Shewanella and with similar $16 \mathrm{~S}$ rRNA copy numbers. It is possible that because they included only 17 species covering all 4 genera, their taxon sampling was too sparse to recover the true pattern. They also removed parts of the $16 \mathrm{~S}$ rRNA alignment that were "ambiguous", further lowering the number of characters, probably the informative characters, in their analysis.

Putting the issue of multiple copies aside, it is not surprising that any of the copies individually is able to group with its species, given that $16 \mathrm{~S}$ rRNA sequences are a significant part of how prokaryotic species are defined. What is more important for evolutionary studies, however, is that because there are multiple copies, and because in the analysis presented here no one single copy among the sampled taxa is found to be positionally homologous, as well as the whole genome topology and the all-copy 16S rRNA topology do not agree, $16 \mathrm{~S}$ rRNA should not be considered a reliable marker for positing evolutionary relationships. Whether it performs well diagnostically is unrelated to this question.

\section{Conclusions}

Recent phylogenetic studies have been published that rely on many more gene loci than has been customary in the past [e.g. 52-54]. These studies also begin to ask and answer questions regarding the number of genes sufficient to obtain the 'true' tree. Gene-tree concordance methods have also been adopted by many to this end $[55,56]$. The study presented here, which takes a different approach, can also begin to add to this discussion. Here, it is shown that unannotated whole genome data can provide excellent raw material for generating hypotheses of historical homology, which can be tested with phylogenetic analysis and compared with hypotheses of gene function. The future possibilities include the ability to quantify lateral gene transfer and gene tree effect, track changing function over gene history and find segments of co-evolving DNA. It is through the combination of methods of phylogenetic systematics and comparative genomics that we can best use the whole genome data to reconstruct the histories of genes, genomes, and taxa.

\section{Acknowledgements}

RBD thanks the following people at the Field Museum of Natural History: Karen Cranston for scripting, Torsten Dikow for reading earlier drafts, and Leo Smith for analysis advice, reading earlier drafts, and hardware support. RBD also thanks Aaron Darling and an anonymous reviewer for their constructive comments. RBD is supported by the Emerging Pathogen Project (to The Field Museum of Natural History and The University of Chicago Institute for Genomics and Systems Biology). Emerging Pathogens Project is funded by The Davee Foundation and The Dr. Ralph and Marian Falk Medical Research Trust. The funders had no role in study design, data collection and analysis, decision to publish, or preparation of the manuscript.

\section{Author details}

'Committee on Evolutionary Biology, The University of Chicago, Chicago, IL, USA. ${ }^{2}$ Division of Fishes, The Field Museum of Natural History, Chicago, IL, USA.

Received: 19 August 2010 Accepted: 12 May 2011

Published: 12 May 2011

\section{References}

1. MacDonell MT, Colwell RR: Phylogeny of the Vibrionaceae and recommendation for two new genera, Listonella and Shewanella. Syst Appl Microbiol 1985, 6:171-182.

2. Euzéby JP: LPSN - List of prokaryotic names with standing in nomenclature (1998-2010). 1998 [http://www.bacterio.net].

3. Chester FD: A Manual of Determinative Bacteriology. New York, The MacMillan Co; 1901.

4. Baumann L, Baumann P, Mandel M, Allen RD: Taxonomy of aerobic marine eubacteria. J Bacteriol 1972, 110:402-429.

5. D'Aoust JY, Kushner DJ: Vibrio psychroerythrus sp. n.: classification of the psychrophilic marine bacterium, NRC 1004. J Bacteriol 1972, 111:340-342.

6. Venkateswaran K, Dollhopf ME, Aller R, Stackebrandt E, Nealson KH: Shewanella amazonensis sp. nov., a novel metal-reducing facultative anaerobe from Amazonian shelf muds. Int J Syst Bacteriol 1998, 48:965-972.

7. Brettar I, Höfle MG: Nitrous oxide producing heterotrophic bacteria in the water column of the Baltic sea: abundance and molecular identification. Mar Ecol Prog Ser 1993, 94:253-265.

8. Ziemke F, Brettar I, Höfle MG: Stability and diversity of the genetic structure of a Shewanella putrefaciens population in the water column of the central Baltic. Aquat Microb Ecol 1997, 13:63-74.

9. Ziemke F, Höfle MG, Lalucat J, Rosselló-Mora R: Reclassification of Shewanella putrefaciens Owen's genomic group II as Shewanella baltica sp. nov. Int J Syst Bacteriol 1998, 48:179-186.

10. Brettar I, Christen R, Höfle MG: Shewanella denitrificans sp nov., a vigorously denitrifying bacterium isolated from the oxic-anoxic interface of the Gotland Deep in the central Baltic Sea. Int I Syst Evol Microbiol 2002, 52:2211-2217.

11. Bowman JP, McCammon SA, Nichols DS, Skerratt JH, Rea SM, Nichols PD, McMeekin TA: Shewanella gelidimarina sp. nov. and Shewanella frigidimarina sp. nov., novel Antarctic species with the ability to produce 
eicosapentaenoic acid (20:5 omega 3) and grow anaerobically by dissimilatory Fe(III) reduction. Int I Syst Bacteriol 1997, 47:1040-1047.

12. Zhao J-S, Manno D, Leggiadro C, O'Neil D, Hawari J: Shewanella halifaxensis sp. nov., a novel obligately respiratory and denitrifying psychrophile. Int J Syst Evol Microbiol 2006, 56:205-212.

13. Gao H, Obraztova A, Stewart N, Popa R, Frederickson JK, Tiedje JM, Nealson KH, Zhou J: Shewanella loihica sp. nov., isolated from iron-rich microbial mats in the Pacific Ocean. Int I Syst Evol Microbiol 2006, 56:1911-1916.

14. Venkateswaran $K$, Moser DP, Dollhopf ME, Lies DP, Saffarini DA, MacGregor BJ, Ringelberg DB, White DC, Nishijima M, Sano H, Burghardt J, Stackebrandt E, Nealson KH: Polyphasic taxonomy of the genus Shewanella and description of Shewanella oneidensis sp. nov. Int I Syst Bacteriol 1999, 49:705-724.

15. Leonardo MR, Moser DP, Barbieri E, Brantner CA, MacGregor BJ, Paster BJ, Stackebrandt E, Nealson KH: Shewanella pealeana sp. nov., a member of the microbial community associated with the accessory nidamental gland of the squid Loligo pealei. Int J Syst Bacteriol 1999, 49:1341-1351.

16. Xiao $X$, Wang $P$, Zeng $X$, Bartlett DH, Wang F: Shewanella psychrophila sp. nov. and Shewanella piezotolerans sp. nov., isolated from west Pacific deep-sea sediment. Int J Syst Evol Microbiol 2007, 57:60-65.

17. Derby HA, Hammer BW: Bacteriology of Butter. IV. Bacteriological Studies on Surface Taint Butter. lowa Agr Expt Sta Research Bull 1931, 145.

18. Zhao J-S, Manno D, Beaulieu C, Paquet L, Hawari J: Shewanella sediminis sp. nov, a novel $\mathrm{Na}+$-requiring and hexahydro-1,3,5-trinitro-1,3,5triazine (RDX)-degrading bacterium from marine sediment. Int J Sys Evol Microbiol 2005, 55:1511-1520.

19. Saltikov CW, Cifuentes A, Venkateswaran K, Newman DK: The ars detoxification system is advantageous but not required for $\mathrm{As}(\mathrm{V})$ respiration by the genetically tractable Shewanella species strain ANA-3. Appl Env Microbiol 2003, 69:2800-2809.

20. Murray AE, Lies D, Li G, Nealson K, Zhou J, Tiedje JM: DNA/DNA hybridization to microarrays reveals gene-specific differences between closely related microbial genomes. Proc Natl Acad Sci USA 2001, 98:9853-9859.

21. Makemson JC, Fulayfil NR, Landry W, Van Ert LM, Wimpee CF, Widder EA, Case JF: Shewanella woodyi sp. nov., an exclusively respiratory luminous bacterium isolated from the Alboran Sea. Int I Syst Bacteriol 1997, 47:1034-1039

22. Perry KA, Kostka JE, Luther GW: Mediation of sulfur speciation by a BlackSea facultative anaerobe. Science 1993, 259:801-803.

23. Lovley DR, Phillips EJP: Novel mode of microbial energy metabolism organic-carbon oxidation coupled to dissimilatory reduction of iron or manganese. Appl Env Microbiol 1988, 54:1472-1480.

24. Sanderson MJ: Construction and annotation of large phylogenetic trees. Aust Syst Bot 2007, 20:287-301.

25. Goloboff PA, Catalano SA, Mirande JM, Szumik CA, Arias JS, Kallersjo M, Farris JS: Phylogenetic analysis of 73,060 taxa corroborates major eukaryotic groups. Cladistics 2009, 25:211-230.

26. Eisen JA, Fraser C: Phylogenomics: intersection of evolution and genomics. Science 2003, 300:1706-1707.

27. dePinna MCC: Concepts and tests of homology in the cladistic paradigm. Cladistics 1991, 7:367-394.

28. Francke U, Taggart RT: Comparative gene mapping: Order of loci on the $x$ chromosome is different in mice and humans. Proc Natl Acad Sci USA 1980, 77:3595-3599.

29. Lee CY, Szittner RB, Meighen EA: The lux genes of the luminous bacterial symbiont Photobacterium leiognathi, of the ponyfish: Nucleotide sequence, difference in gene organization, and high expression in mutant Escherichia coli. Eur J Biochem 1991, 201:161-167.

30. Eisen JA, Heidelberg JF, White O, Salzberg SL: Evidence for symmetric chromosomal inversions around the replication origin in bacteria. Genome Biology 2000, 1:research0011.

31. Read TD, Brunham RC, Shen C, Gill SR, Heidelberg JF, White O, Hickey EK, Peterson J, Utterback T, Berry K, Bass S, Linher K, Weidman J, Khouri H, Craven B, Bowman C, Dodson R, Gwinn M, Nelson W, DeBoy R, Kolonay J, McClarty G, Salzberg SL, Eisen J, Fraser CM: Genome sequences of Chlamydia trachomatis MoPn and Chlamydia pneumoniae AR39. Nucleic Acids Res 2000, 28:1397-1406.

32. Woese CR, Fox GE: Phylogenetic structure of the prokaryotic domain: the primary kingdoms. Proc Natl Acad Sci USA 1977, 74:5088-5090.
33. Gogarten JP: The early evolution of cellular life. Trends in Ecol Evol 1995, 10:147-151.

34. Morandi A, Zhaxybayeva O, Gogarten JP, Graf J: Evolutionary and diagnostic implications of intragenomic heterogeneity in the $16 \mathrm{~S}$ rRNA gene in Aeromonas strains. J Bacteriol 2005, 187:6561-6554.

35. Darling AE, Mau B, Perna NT: progressiveMauve: Multiple Genome Alignment with Gene Gain, Loss and Rearrangement. PLOS ONE 2010, 5 : e11147.

36. Darling AE, Miklós I, Ragan MA: Dynamics of genome rearrangement in bacterial populations. PLoS Genetics 2008, 4:7.

37. Stothard P, Wishart DS: Circular genome visualization and exploration using CGView. Bioinformatics 2005, 21:537-539.

38. Katoh K, Misawa K, Kuma K, Miyata T: Mafft: a novel method for rapid mutliple sequence alignment based on fast fourier transform. Nucl Acid Res 2002, 30:3059-3066.

39. Goloboff P, Farris JS, Nixon KC: TNT: a free program for phylogenetic analysis. Cladistics 2008, 24:774-786.

40. Stamatakis A: RAxML-VI-HPC: maximum likelihood-based phylogenetic analyses with thousands of taxa and mixed models. Bioinformatics 2006, 22:2688-2690.

41. Saitou N, Nei M: The neighbor-joining method: a new method for reconstructing phylogenetic trees. Mol Biol Evol 1987, 4:406-425.

42. Drummond AJ, Ashton B, Cheung M, Heled J, Kearse M, Moir R, StonesHavas S, Thierer T, Wilson A: Geneious v4.8.3. 2009 [http://www.geneious. com].

43. Nixon KC: The parsimony ratchet, a new method for rapid parsimony analysis. Cladistics 1999, 15:407-414.

44. Goloboff PA: Analyzing large data sets in reasonable times: Solutions for composite optima. Cladistics 1999, 15:415-428.

45. Sparks JS, Smith WL: Phylogeny and biogeography of cichlid fishes (Teleostei: Perciformes: Cichlidae). Cladistics 2004, 20:501-517.

46. Dikow RB: Systematic relationships within the Vibrionaceae (Bacteria: Gammaproteobacteria): steps toward a phylogenetic taxonomy. Cladistics 2011, 27:9-28.

47. Cavalli-Sforza LL, Edwards AWF: Phylogenetic analysis. Models and estimation procedures. Amer J Human Genet 1967, 19:233-257.

48. Goloboff PA: Random data, homoplasy and information. Cladistics 1991, 7:395-406.

49. Konstantinidis $K T$, Serres MH, Romine MF, Rodrigues JLM, Auchtung J McCue L, Lipton MS, Obraztsova A, Giometti CS, Nealson KH, Fredrickson JK, Tiedje JM: Comparative systems biology across an evolutionary gradient within the Shewanella genus. Proc Natl Acad Sci USA 2009, 106:15909-15914.

50. Haggerty LS, Martin FJ, Fitzpatrick DA, McInerney JO: (2009) Gene and genome trees conflict at many levels. Phil Trans R Soc B 2009, 364:2209-2219

51. Liao D: Concerted evolution: molecular mechanism and biological implications. Am J Hum Genet 1999, 64:24-30.

52. Di Bonaventura MP, Lee EK, DeSalle R, Planet PJ: A whole-genome phylogeny of the family Pasteurellaceae. Mol Phylo Evol 2010, 54:950-956.

53. Hackett SJ, Kimball RT, Reddy S, Bowie RCK, Braun EL, Chojnowski JL, Cox WA, Han K-L, Harshman J, Huddleston CJ, Marks BD, Miglia KJ, Moore WS, Sheldon FH, Steadman DW, Witt CC, Yuri T: A phylogenomic study of birds reveals their evolutionary history. Science 2008, 320:1763-1768.

54. Rokas A, Carroll SB: More Genes or More Taxa? The Relative Contribution of Gene Number and Taxon Number to Phylogenetic Accuracy. Mol Biol Evol 2005, 22:1337-1344.

55. Liu L: BEST: Bayesian estimation of species trees under the coalescent model. Bioinformatics 2008, 24:2542-2543.

56. Ané $C$, Larget B, Baum DA, Smith SD, Rokas A: Bayesian estimation of concordance among gene trees. Mol Biol Evol 2007, 24:412-426.

\section{doi:10.1186/1471-2164-12-237}

Cite this article as: Dikow: Genome-level homology and phylogeny of Shewanella (Gammaproteobacteria: Iteromonadales: Shewanellaceae). BMC Genomics 2011 12:237. 